\title{
From emergence to maintenance A model for identifying and interpreting strategic issues
}

\author{
P. Human and P. Berthon \\ Graduate School of Business, University of Cape Town, Rondebosch 7700, Republic of South Africa
}

Received 1 March 1990; accepted 2 July 1990

\begin{abstract}
In this paper an analytical model for identifying and delineating strategic issues is developed. The traditional SWOT approach is criticised. A model is developed using grounded theory from research done on 119 top South African companies. The two major delineating factors and thus axes of the model are importance and uncertainty. The article is concluded by considering the academic and practical implications of the model and the associated research.
\end{abstract}

'n Analitiese model vir die identifisering en onderskeiding van strategiese faktore word in hierdie artikel ontwikkel. Die tradisionele 'SWOT'-model word gekritiseer. 'n Model is ontwikkel deur gebruik te maak van induktiewe teoriekonstruksie wat gebaseer is op empiriese navorsing wat in 119 Suid-Afrikaanse maatskappye gedoen is. Die twee onderskeidende dimensies wat gebruik word is belangrikheid en sekerheid. Die artikel word afgesluit met 'n besinning oor die praktiese en akademiese implikasies van die voorgestelde model.

\section{Introduction}

'The tools of the mind become burdens when the environment which made them necessary no longer exists.' - Henri Bergson

In strategic management, as in all fields, the maintenance of congruency between ideas and experiential 'reality' is of elemental importance. For, whilst our environment is changing with increased rapidity, many of our ideas, models and paradigms are rooted in another time and place. The hiatus between practical reality and concepts has grown wide.

Strategy formulation has its foundations in the identification and delineation of strategic issues; inappropriate models or tools at this stage nullify the effectiveness of the entire strategic process. In this article, we argue, that traditional methodologies for the delineation of strategic issues are based on inappropriate conceptions of the business context. The limitations of this premise are illustrated by the inexpediency of the traditional SWOT approach to the delineation of strategic issues.

Strategy formulation is essentially a decision-making process. Defined by Mintzberg (1983: 114) as a 'commitment to action', decision-making can be said to be the cognitive process of problem solving necessary to and preceding purposeful action. It is useful to split this process into the various conceptually distinct stages of: problem awareness; problem recognition; development of solutions; evaluation of solutions; and selection of the most appropriate solution. In as much as this paper deals with identification and delineation of strategic issues, it is thus concemed predominantly with the initial stages of the decision-making process; that is the awareness, problem recognition and development stages. Primary attention is given to problem formulation, whilst the stages of evaluation, selection and final operationalisation are dealt with as a secondary concern.

Strategic issues are complex and numerous; they are temporally and spatially variant, and are characterised by varying degrees of equivocality. Thus any new approach to the delineation of strategic issues must take into consideration all the above factors in an attempt to validly map the strategic context. The model proposed in this article attempts to provide managers with the 'tools of the mind' congruent with today's business environment. Moreover, the model illustrates the theory that strategy is quintessentially a learning process. The model evolved from today's business context, using grounded theory. The research was undertaken in South Africa, where the asperities of normal societies are greatly accentuated.

\section{Identification and delineation of strategic issues}

There is a variety of approaches to problem recognition in the literature on strategic management (Murphy, 1989). Strategic issues are complex, characterised by a high degree of interconnectivity, and are multivariate in nature. The delineation of strategic issues, using a meaningful framework, is the attempt to crystalise this initially amorphous complexity. Nevertheless, despite being the foundation upon which decision making and strategy formulation is based, delineation of issues is the Cinderella of the art.

Traditional delineation methodologies are typified in the SWOT approach, where strategic issues are divided into internal and external items. Internal issues being categorised as strengths and weaknesses whilst external issues are viewed as threats or opportunities.

However, the delineation of issues in this way has a number of encumbrances. First, the SWOT model evolved from and perpetuates what will be termed organocentricism. The organocentric paradigm is the view that the organisation is the centre of reality, and that the environment is a separate objective entity distinct from the organisation.

However, today organisations are recognised to be 'open', inextricably interwoven and thus interdependent with the complex fabric of their environment (Emery, 
1969); further, this fabric is fast becoming global in nature. Organisations can no longer be viewed as separate, only as part of their wider environment. The current emphasis on the customer and service suggests a growing awareness of this interdependence. Moreover, this interconnectivity renders obsolete the simplistic threat-opportunity, strengths-weaknessclassifications.

Second, especially with ambiguous and paradoxical issues, the SWOT classification is both arbitrary and potentially misleading. An issue can be both opportunity and threat (in fact this is typically a norm), while strengths and weaknesses are situational and not absolutes. Indeed it may be postulated that all issues of internal and external change carry within them the seeds of both strength and weakness, opportunity and threat.

For example, the change in consumer life style is manifestly both a threat and an opportunity; a threat to an old product line, but an opportunity to develop new and innovative products to meet the needs of the the new life style. Similarly, a young untrained workforce can be both a strength and a weakness; the weakness manifesting as inexperience, the strength appearing as the relative ease in which the workforce will adapt and change to new skills and ways of working.

Further, the specific assignment of strengths and weaknesses to internal issues, whilst external items are classified as threats and opportunities is manifestly limiting. It discourages viewing internal issues as opportunities, as for example one could (and should) view the skill development of one's employees (Goodbrand, 1989).

Third, the SWOT approach encourages the adoption of a static mindset, or what may be termed labelism. For it is reassuring to be able to pigeon hole issues: establish order where there was disorder. However it places a false layer of certainty over that which is often intrinsically ambiguous; it reduces manager's ability to perceive the inherent possibilities in a given situation. This is exacerbated by the very human failing of seeing stereotypes rather than the underlying 'reality'. Once classified the label becomes the focus of managerial attention, rather than the issue per se. This is particularly counterproductive in times of rapid change. Strategic issues are intrinsically dynamic, having no respect for labels. Consequently the fluidity of issues through time must be appreciated: strengths become weaknesses, threats become opportunities. All classifications and labels have a tendency to distort the 'reality' of the situation they are attempting to grasp. However there is the question of degree, which in the SWOT methodology is exacerbated by the oversimplificationrendered by polar labels.

(By this we mean that classification which involves diametrically opposed opposites, such as good-bad, strength-weakness etc., encourages polarity of mindset towards issues. Moreover, it obfuscates the realisation that issues may lie on a continuum, rather than being diametrically opposed.)

Fourth, and potentially most debilitating, is that so wide spread is the implicit assumption, in both academic and business spheres, of the intrinsic expedience of the
SWOT methodology, that it has become a paradigm in itself. Academics are researching the characteristics of threats and opportunities per se, as if they were inherent attributes of strategic issues (e.g. Jackson \& Dutlon, 1988), rather than merely subjective conceptual categories, created by and employed in the classification of strategic issues.

The conceptual model developed in the ensuing pages offers a different perspective on the delineation of strategic issues. Moreover it addresses, in part, the limitations of the SWOT model.

\section{Introduction to the model}

The methodology for developing the model resides on two levels. The basic framework was developed deductively, whilst the model was augmented and refined through grounded theory (Glaser \& Strauss, 1967).

Grounded theory is simply a method for theory construction by which, after selecting a specific area for study, one gathers data (qualitative as well as quantitative) and then identifies patterns therein. This is in juxtaposition to the deductive scientific method where hypotheses are developed and data used to verify or reject those hypotheses.

In the consideration of a more pertinent classification of strategic issues it was decided to concentrate on perceptions of relative importance. Managers consciously or subconsciously weigh issues according to the perceived impact, direct or indirect, that each will have on strategic decision-making and emergent strategies. Thus perceived relative importance becomes one axis of the model.

The second dimension to the delineation of strategic issues evolved from the nature of today's business environment. The stability and predictability of the 1950's and 1960's has been replaced by ambiguity, paradox and an increasing rate of change. This manifests as a basic uncertainty in perception of issues and their repercussions. Thus the degree of relative uncertainty of the issue is used as the other axis of the model (see Figure 2). Mason and Mitroff (1981) use the same criteria to classify assumptions made in strategic planning.

The 'modus operandi' of the model resides on two levels. First, the strategic issues themselves are generated. This is undertaken either by the managers themselves, or by a panel of experts generating the list of issues. Typically a combination of the two is utilised, with managers augmenting a pre-compiled list with situationally specific issues. Second, the issues are placed within the model by managers assigning subjective values for levels of importance and uncertainty to each of the issues.

\section{The study: design, Implementation \& results Design}

The second phase of development of the model was the application of empirical data. This study in turn comprised two elements or phases. First, a panel of 
experts consisting of business school academics and senior executives were asked to identify the major strategic issues facing South African management today. The resulting list was also augmented by reference to appropriate literature (Porter, 1985 \& Quinn, 1980). The second element of the study entailed the design and administering of a questionnaire to a sample of managers. The survey was designed to elicit ratings, in terms of importance and uncertainty, on the issues identified in the first part of the study. A'scale of low, medium and high was used to categorise ratings. The issues were explicitly divided into internal and external factors.

\section{Implementation}

Questionnaires were sent to a randomly selected sample of companies listed on the Johannesburg Stock Exchange (JSE). The respondents were all CEO's of South African companies. Altogether 119 companies were involved and each of the various JSE sectors was represented (see appendix for sample characteristics).
Results

For the sample as a whole, the average rating of each strategic issue in terms of importance and uncertainty, was transposed onto a simple visual plot. The issues and their respective positions in the model are shown in Figure 1.

\section{Low importance, high uncertainty quadrant}

A distinction between two types of issues occupying this quadrant can be made. First, there are those long-term issues sufficiently nebulous and outside management's ambit of control to be deemed unimportant. A typical example of this would be climatic conditions. Second, there are the genuinely new issues, such as AIDS and sanctions, whose impact is as yet unascertained but are considered sufficiently distant, whether temporally (e.g. AIDS) or spatially (e.g. relationships with neighbouring countries) as to rate as unimportant.

Thus uncertain, unimportant issues may be said to have an 'emergent' quality; for tomorrow's salient issues surface here, as did today's. It is the region where

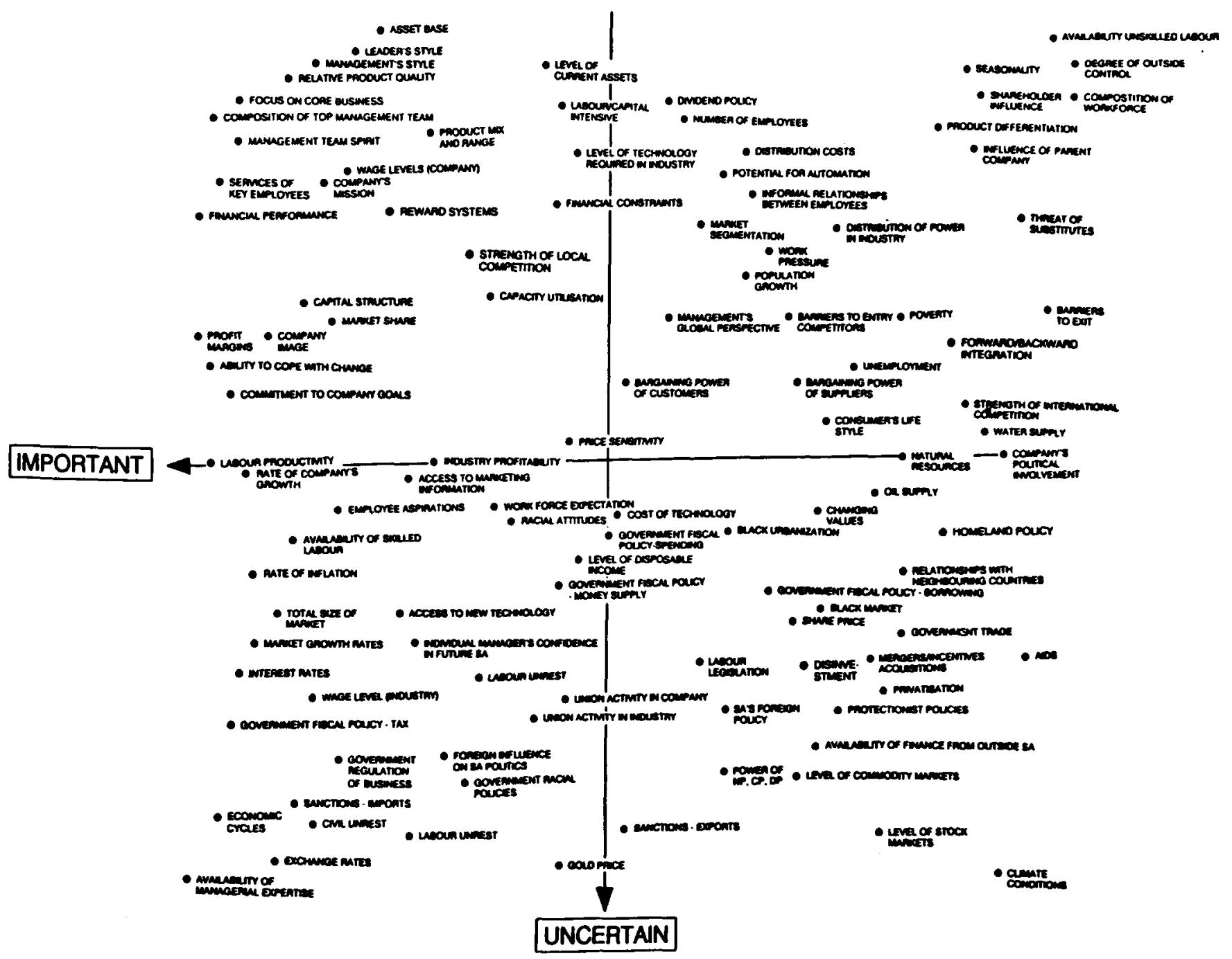

Figure 1 Perceptual map of strategic issues 
virtually all new strategic issues emerge. They appear on the horizon of management's strategic perception. They are characterised by a high degree of uncertainty, but are deemed far enough away to be of little immediate concern.

Specific groups of issues worthy of comment in this sector include natural resources, the black market, relations with other countries.

The fact that natural resources are seen as unimportant and undifferentiated in terms of certainty, is testimony to South Africa's liberal endowment of these items. European and Japanese managers would perhaps perceive this issue to lie in the important-uncertain quadrant. Testimony to this postulation is the massive effort in Japan to produce a 'Universal' material, thus greatly reducing the country's dependence on imported natural resources (Van Wyk, 1988).

Due to the rapidly growing black population, issues such as the black market, changing values and homeland policy are all factors which may ascend in importance with great rapidity in the near future. The perception of these items in this quadrant also suggests an ambivalence to the fact that business is a part of a wider societal fabric.

The fact that South Africa's foreign policy, disinvestment, protectionist policies, availability of finance from outside South Africa, sanctions, and relationships with neighbouring countries are all seen as relatively unimportant strategic issues, suggests that South African managers adopt a relatively short time horizon with respect to strategic planning. The fact that time horizons contract when organisations perceive themselves to be in difficulty may not be entirely unassociated. It is also characteristic of the insular 'fortress' mentality of organocentrism; for South Africa's longer term business future is closely entwined with the global economy and thus foreign relations.

\section{High importance, high uncertainty quadrant}

These issues are the thoms in the flesh of management. They are the 'wicked' (Mason \& Mitroff, 1981) issues which resist simple solutions and consequently place most strain on management expertise. Labour unrest, sanctions, exchange rates, availability of managerial expertise, economic cycles and the govemment's racial policies are the issues of the day. Moreover these are the issues which management must come to terms with if they are to ensure the long term survival of their organisations.

These issues are characterised by a high level of ambiguity and complexity, but are within the immediate to short time horizon of strategic vision; thus management must 'formulate' appropriate strategies for dealing with such issues, and this formulation is characterised by a degree of urgency. These are potentially the most debilitating strategic issues for management, and an area where there is a pronounced dearth of appropriate tools and methodologies for coping. For obviously, the greater the uncertainty, the more difficult it is to proceduralize activity by preplanning a response.

Of interest is the group of sociological issues within this quadrant. These include employee aspirations, workforce expectations and racial attitudes, with labour and civil unrest being rated as relatively more uncertain. The relatively low importance assigned to racial auitudes is of some concern. It signifies relative ambivalence to such a pertinent issue. One would have thought that an issue so germane to South Africa's longer term future, would rate more highly in terms of importance.

The predominance of issues with sociological connotations within this quadrant may reflect the wider uncertainty within South African society. However these issues are typically perceived as of relatively less importance than the economic factors within the quadrant (e.g. rate of inflation, government fiscal policy, interest rates etc.). Manifestly, managers view organisations as primarily economic organs, rather than social ones.

\section{High importance, low uncertainty}

These are relatively well understood issues whose control is systematized and consequently whose outcome is relatively certain. They also constitute the group of issues which tend to occupy the largest portion of management's time, due no doubt to their perceived centrality and proximity to management.

Financial performance, company image, focus on core business are all typical of the more prominent issues in management's current daily program.

Issues of low uncertainty and high importance, are typically the problems which management science is able to solve. Management feels in control of these issues through understanding and proximity. These are the issues which are in the process of being implemented or which require constant attention. The models, procedures and processes are well known and correct 'implementation' of the appropriate strategy is the main need.

Of additional interest is the overall nature of the issues in this sector. They may, without exception, be described as introspective, that is inward looking.

\section{Low importance, low uncertainty quadrant}

Corresponding to-the unimportant and relatively certain quadrant, the maintenance issues are more akin to procedural issues than genuine strategic ones. These issues have been systematized and take up little of management's time. The influence of the parent company, shareholder influence, degree of outside control, threat of substitutes, barriers to exit and distribution of power within the industry are all examples of issues which are regarded as unproblematic and in part solved. They are issues of day to day 'maintenance'.

What is of predominant interest, is that population growth, poverty, unemployment and water supply are seen as being relatively unimportant strategic 'business' 
issues. This is probably because they are deemed outside the ambit of business concern, and thus are testimonies to the still widespread 'organocentric' paradigm (i.e. the business sees itself proudly separate from its environment).

One can understand that these factors are fairly certain (at least in the short term), but it appears almost irresponsible to deem them as relatively unimportant. Such a view is only possible given a relatively short strategic decision-making horizon.

For example, poverty in South Africa is rampant. The country has the highest Gini coefficient (a measure of the disparity between rich and poor) of any of the 57 countries for which data is available; and it is ... necessary to be quite clear that in the struggle against poverty there is a crucial role to be played by private enterprise' (Wilson \& Ramphele, 1989); obviously managers think otherwise.

\section{Refinement of the model}

The model may be further enhanced by the consideration of how it relates to the decision-making process, of awareness to selection, enunciated earlier in this article.

The progression from the 'emergence' to the 'formulation' quadrant corresponds to the awareness and problem recognition stages in the decision-making process. The initial ambivalence to an issue dissolves as information on the issue is gathered and it becomes correspondingly of greater importance.

The development stage equates directly with the 'formulation' quadrant and it is here that most of the 'thinking' about the problem occurs. It is the peak of mentational activity.

The evaluation and selection stages corresponds to the motion into the 'implementation' quadrant; this is the 'operationalisation' of potential solutions, where the fruit of management's mentation is enacted (Weick, 1979), with a corresponding increase in certainty about the issue.

The final passage from the 'implementation' to the

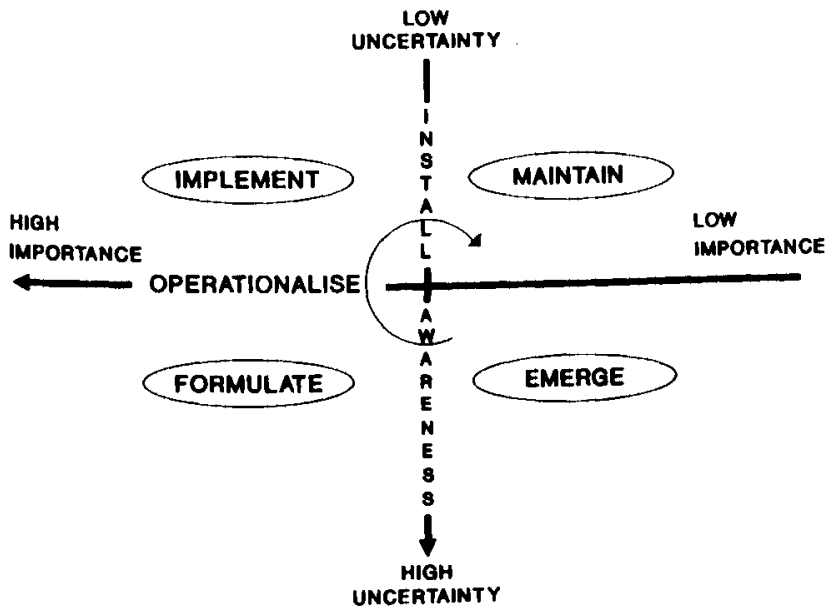

'maintenance' quadrants goes beyond the main decisionmaking process and equates to the 'installation' into diumal procedure and the effective negation of the problem as a strategic issue. An enhanced version of the model is provided in Figure 2.

From the preceding discussion, the time element inherent in the model is apparent. Issues will tend to drift or be forced clockwise around the model with time. Issues initially emerge in the lower-right quadrant, where they enter management's sphere of cognition. The issues are novel and thus litle is known about them. As the nature of an issue begins to crystalise, it is either dismissed from management's ambit of consideration (and hence disappears off the model) or its inherent bearing on the organisation is appreciated and is thus perceived as more important.

On reaching the important-uncertain quadrant managers formulate a range solutions, but are still uncertain of the outcome. Once an issue has been successfully dealt with, confidence returns and the issue is perceived as certain, although still of high importance. Eventually over time, an issue may recede in importance, becoming part of day to day management, and thus a maintenance issue; which in tum renders it non-strategic.

Consequently, how an issue moves within the model depends largely on whether management adopts a reactive or proactive stance towards that issue.

Management's aim and purpose is to build awareness of issues in the emergence quadrant. Then to systematize issues of high importance and uncertainty in such a way as move the issue into the upper quadrants. This systematization of uncertainty, suggests that the upper quadrants are characterised by a structured decisionmaking context, whilst the lower, by an unstructured one (Mintzberg, Raisinghani \& Theoret, 1976).

Finally the strategic issue model can be related to a learning process. If one considers how a child, adult or organisation learns to respond to a new phenomenon, four steps are discernable: instinctual reaction, thinking, enactment and habit. These four steps may be classified using the dimensions of consciousness and action. The model developed here is similar to that of Young (1976).

The above process may be elucidated as follows. On



Figure 3 The strategic learning process 
encountering a new phenomena one's first reaction is instinctual; one runs away from the charging lion. This reaction is unconscious and purely reflexive.

Having gained safety, one reflects upon the experience, employing one's thinking function in the cognitive process of gathering data about, and trying to understand the phenomenon. This is still a reaction to the initial contact, but it is now a conscious reaction. Having thought about and analysed the experience one takes specific action to either avoid the lion or to render it harmless; that is one enacts the solution(s) found in the thinking phase.

This may take the form of moving to a new area or carrying a rifle for protection. Thus reaction now becomes conscious action. Finally the carrying of a rifle becomes habit: conscious action becomes unconscious action.

The above model equates very closely with the strategic issue model (Figure 3). Organisations typically react instinctually to the new issues entering the emergent quadrant. A typical example was the initial reaction to AIDS, where if an employee contracted the disease he/she was immediately removed. This action was instinctual, based on fear.

The formulation quadrant corresponds to the thinking stage in the learning process. The initial instinctual reaction gives way to cognitive attempts to formulate solutions. Obvious examples include labour unrest and economic cycles.

The implementation quadrant equates to the enactment phase where solutions to problems are implemented through enactment. Reaction translates into action to cope with issues like company image and reward systems.

Finally, the maintenance quadrant corresponds to the habit stage in the leaming process. The handling of issues such as seasonality and consumer life style have become so routine that the machinery of the organisation deals with them with little conscious attention from top management.

\section{Further discussion of the findings}

Having taken a panoramic view of the issues, we will now focus on, and dissertate in more depth the salient points which have surfaced during the aforegoing discussion.

\section{Internal and external factors}

Of interest was whether the model differentiated internal and extemal issues; and further, if importance and uncertainty correlate meaningfully within the two groups. The grouping and relative positions of internal and external issues are shown in Figure 4.

From this plot, clear patterns are discernible. First the intemal issues are grouped mainly in the upper quadrants with a bias towards being classified as important. That is they are characterised by a high level of certainty and are considered important by managers.

This may be a manifestation of the Pollyanna Principle (Matlin \& Stang, 1978) which states that issues one can control (i.e. internal ones) are deemed as highly important, whilst issues over which one has little control are viewed as less important. Regression analysis revealed no correlation of importance and uncertainty among the internal issues.

However, the external issues are scattered along the inclined diagonal. Correlation analysis confirms this, yielding a Pearson ' $r$ ' statistic of 0.58. This is of significance for it reveals uncertainty is correlated with importance. Thus for example, the issue of availability of management expertise is classified as highly uncertain and highly important, whilst availability of unskilled labour is deemed certain and correspondingly unimportant.

\section{Stable and mobile issues}

From the outset, realisation of the topicality of the model is essential. The survey is a 'snap shot' of perceptions, and therefore inextricably linked to the moment in time that it was performed. This in turn highlights the mobility of issues and the temporal element inherent in the model.

Thus, one can distinguish between those issues which move within the model over time, and those which exhibit continuity of position. One may postulate that financial performance and profit margin will maintain their positions of high importance and relative certainty, whilst issues such as AIDS may move rapidly from uncertain and unimportant, to certain and important.

Further, the model highlights the interactive nature of strategic issues and strategic decision-making. The adoption of a passive or proactive stance towards an issue, by management, will influence its subsequent motion within the model. For example, labour unrest will remain highly uncertain if managers adopt a passive stance. However, if specific action is taken, like for example the introduction of, and long term commitment

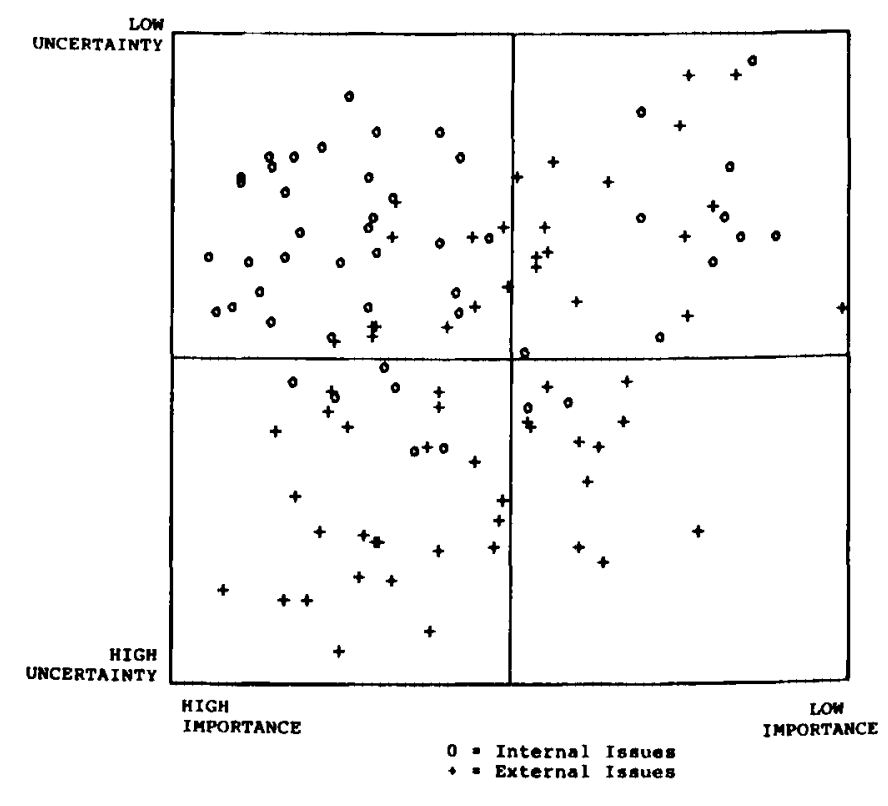

Figure 4 Relative position of internal and external issues 
to participative management and black advancement, this issue may be 'short circuited'; thereby moving it relatively quickly to the certain, unimportant quadrant.

Organisations are continually attempting to minimise uncertainty. This takes many forms, from attempts to control the market and subjugate the wider environment, to utilisation of new methodologies for coping with uncertainty. Thus there will be a tendency for factors to be pushed from uncertain to certain quadrants.

\section{Specific and global issues}

In the study the perceptions of the CEO's of a wide range of public companies are examined. The resulting positioning of issues may be viewed as an economy wide average for the larger organisations. Similar studies, within specific JSE sectors, would reveal differing perceptions of issues.

Thus the model facilitates the identification and differentiation of industry specific issues and global issues. For example whilst climatic conditions are designated unimportant from a global perspective, from the specific agriculture sector it would rate as highly important, if similarly uncertain.

\section{Type of problem}

The model differentiates what Mason \& Mitroff (1981) term 'wicked' and 'tame' problems. Tame problems are characterised by separability, reducability and linearity. Wicked problems exhibit interconnectivity, ambiguity and uncertainty. Thus, as would be expected, the wicked problems tend to gravitate towards the lower quadrants and high uncertainty (e.g. exchange rates); tame problems, on the other hand, tend to do the inverse, by congregating in the upper quadrants (e.g. level of current assets).

\section{Implications}

The list of strategic issues describes the context within which strategic decisions are made. The completeness and validity of this context are thus of critical importance to the solution of strategic problems. We have seen that this context is complex in terms of both the number of issues, and types (i.e. quantitative, qualitative, certain, important, long term, short term). The strength of our particular approach is that it attempts to generate as complete a description of the strategic context as possible.

By first asking managers to generate strategic issues (i.e. issues which influence or may influence strategic decision-making) through brainstorming, then to rate them, and then, and only then, to label issues, overcomes the 'labelism' problem inherent in SWOT. To look for an opportunity or threal, strength or weakness, immediately limits the range of possible issues.

Our proposed model also consciously includes the uncertain and problematic, whereas other approaches would be inclined to work with only known certainties; complexity and uncertainty are the foundations of our model. It is our contention that although any classification scheme tends to distort reality through the imposition of generalised categories, our model attempts to produce a realistic picture of the strategic context.

What is also of interest is that strategic issues are normally interconnected by relationships of covariance or causality. Our model may be further explored by searching for such relationships. For example, increasing poverty in South Africa may imply a steady erosion of the market (thus a long term environmental issue affects an internal short term business issue).

The 'discovery' of such relationships across quadrants may provide the academic and manager with a much deeper understanding of the strategic context than possible in the case of a 'shopping list' of strategic issues.

The rise of management science bears testimony to the success of the positivistic epistemology in dealing with tame (hard, quantitative) problems. The upper quadrants of the model are replete with strategic issues which positivistic methodologies handle with relative ease (e.g. capacity utilisation, financial performance etc.).

Further, the 'soft' qualitative issues in the upper quadrants such as management style, commitment to company goals, team spirit etc. bear witness to the success of the culture approach and its phenomenological epistemological underpinnings.

However, positivism, and to a lesser extent phenomenology, are limited in their ability to deal with the wicked problems in the lower quadrants. For interconnectivity and ambiguity make problem formulation and cause-effect relationships difficult if not impossible to ascertain with these types of issue.

Thus the challenge for academics and businessmen in the future will be to develop new concepts and tools to enable people to cope with the epistemological 'terra incognita' of the lower quadrants.

It has been stated that mobile issues have a tendency to move in a clockwise direction around the model; further that management in an attempt to decrease uncertainty and proceduralise activity, consistently reinforce this process by pushing issues towards greater certainty and lower importance. This process can be seen as an underlying urge to 'gain control' over both organisation and environment. Managers (as does Western society in general) dislike uncertainty because it means that they are no longer in control.

Possibly the lesson and challenge for management (and Western society in general) will increasingly become that of learning to accept uncertainty and its accompanying ambiguity and paradox; especially as all indications point towards an escalation of change and thus uncertainty in the years ahead. However to cope with such situations may require the reliance on, and consummate development of, the neglected psychic functions of feeling and intuition.

The epistemological and methodological basis of tomorrow's management theory (and practice) may be characterised more by anarchy than procedure, process rather than technique. 
Moreover, perhaps the active elimination of uncertainty, is actually counterproductive. For as shown in the strategic leaming process, (see Figure 4) the culmination of the cycle is habit formation. Now habit formation may be efficacious in times of relative stability, but can be counterproductive during periods of rapid change or high competition.

Too often is habitual procedure continued long after its congruence with the environment has waned. This 'habit incongruence' is highly perilous. For the danger of habit is that one is no longer conscious of, and thus able to question the appropriateness of, one's actions.

Organisational history is replete with examples of habit incongruence. The successful penetration of the American car market by the Japanese in the 70's rests in no small part with the home manufacturers ceasing to question the appropriateness of building large, heavy automobiles with voracious appetites for fuel.

Thus the learning process should be complemented by an 'unlearning process' where one becomes conscious of, and begins to question habitual action. This unlearning can be seen in the rise of the 'questioning culture' (Faull, 1988).

The congruence between the strategic issue model and the learning process highlights an important feature of strategy formulation in times of rapid change. For it highlights the fact that strategy is intrinsically a learning process. Traditional models and approaches to strategy have been characterised by a high degree of procedure and are ultimately prescriptive in nature. Our model eschews this tendency, and can be seen as a tool to assist managers in learning to learn.

The empirical data generated in the course of the development of the model also describes some interesting features of the perceptions of CEO's of South African companies. The general orientation is organocentric and short term; focusing on the internal and mostly 'hard' business factors.

It is apparent from our description that it is the uncertain and social issues, especially the external socioeconomic and political environment, that are the issues that our sample of CEO's are least adept at handling. The direct relationship between uncertainty and importance in external issues, furthermore illustrates their plight and the need to develop approaches to the handling of these 'wicked' problems.

\section{References}

Emery, F.E. (ed.). 1969. Systems thinking. Harmondsworth: Penguin.

Faull, N. 1988. Climate and attitude prerequisites for productivity. Pre-publication paper. Cape Town: Graduate School of Business, University of Cape Town.

Glaser, B.G. \& Strauss, A.L. 1967. The discovery of grounded theory. Chicago: Aldine Press.

Goodbrand, K.A. 1989. Framework for business opportunity search. Tochnical Report. Cape Town: Graduate School of Business, University of Cape Town.
Huber, P. 1980. Managerial decision making. Scott, Foresman \& Co.

Human, P. 1989. Concept and method in strategy formulation research. Working paper. Cape Town: Graduate School of Business, University of Cape Town.

Jackson, S., Dutton, J. 1989. Discerning threats and opportunities. Administrative science quarterly, Vol. 33: 370-387.

Mason, R., Mitroff, 1. 1981. Challenging strategic planning assumptions. New York: J. Wiley and Sons Inc.

Matlin, M., Stang, D. 1979. The Pollyanna principle: selectivity in language, memory and thought. Cambridge, Mass: Schenkman.

Mintzberg, H., Raisinghani, D., Theoret, A. 1976. The structure of unstructured decision processes. Administrative science quarterly, Vol. 21: 246-275.

Mintzberg. H. 1983. Power in and around the organisation. Englewood Cliffs, New Jersey: Prentice Hall.

Murphy, J.J. 1989. Identifying strategic issues. Long Range Planning, Vol. 22, 2: 1O1-105.

Porter, M.E. 1985. Competitive advantage: creating \& sustaining superior performance. New York: Free Press.

Quinn, J.B. 1980. Strategies for change: logical incrementalism. Homewood, Illinois: Richard D. Irwin.

Van Wyk, R.J. 1989. Interview. Cape Town: Graduate School of Business, University of Cape Town.

Weick, K. 1979. The social psychology of organization reading. M.A.: Addison-Wesley.

Wilson, W. \& Ramphele, M. 1989. Uprooting poverty - the South African challenge. David Philip.

Young, A.M. 1976. The geometry of meaning. Delacorte Press.

\section{Appendix: sample characteristics}

A breakdown by sector and turnover of the companies who participated in the research.

Sector:

$\begin{array}{lc} & \% \\ \text { Financial } & 15.4 \\ \text { Mining } & 12.8 \\ \text { Manufacturing } & 47.0 \\ \text { Retail } & 13.6 \\ \text { Development capital } & 11.2\end{array}$

$100.0 \quad \mathrm{~N}=119$

Annual tumover:

\begin{tabular}{llll}
\multicolumn{1}{c}{ Rm } & & $\%$ & \\
$2-20$ & & 14.5 & \\
$21-50$ & & 16.3 & \\
$51-300$ & & 20.5 & \\
$301-1000$ & & 22.3 & \\
over 1000 & & 14.5 & \\
not reported & & 11.9 & \\
& 100.0 & & $\mathrm{~N}=119$
\end{tabular}

